\title{
ТРАНСФОРМАЦИЯ ПРЕДПРИНИМАТЕЛЬСКИХ ЭКОСИСТЕМ В УСЛОВИЯХ ЭКОНОМИЧЕСКИХ ОГРАНИЧЕНИЙ
}

\section{THE TRANSFORMATION OF BUSINESS ECOSYSTEMS IN THE CONTEXT OF ECONOMIC CONSTRAINTS}

\section{A. Golovina \\ R. Levchenko \\ A. Aleksina}

Summary: The article is devoted to the study of the issues of transformation of entrepreneurial ecosystems during periods of crises. The authors conduct a study of global macrofactors affecting entrepreneurial systems in the shock of 2020 and propose their own model of the capacity of entrepreneurial potential associated with the tensions and resistances that are emerging in entrepreneurship at the present time. As a result, it is substantiated that against the background of the current events, Russian entrepreneurship can act not only as a driver of post-crisis recovery, but also become a locomotive for re-industrialization of the economy, and its role in strengthening the trend of economic growth can be activated through the successful modification of entrepreneurial ecosystems and avoiding negative institutional practices.

Keywords: entrepreneurial ecosystem, transformation of the entrepreneurial landscape, model of succession of entrepreneurial potential.
Головина Алла Николаевна

Д.э.н., профессор, Уральский государственный экономический университет

Левченко Роман Юрьевич К.э.н., доцент, Уральский государственный экономический университет vshko@inbox.ru

Алексина Анна Сергеевна К.э.н., дочент, Уральский государственный экономический университет

Аннотация: Статья посвящена изучению вопросов трансформации предпринимательских экосистем в периоды кризисов. Авторы проводят исследование глобальных макрофакторов, влияющих на предпринимательские системы в условиях шока - 2020, и предлагают свою авторскую модель емкости предпринимательского потенциала, связанную с напряжениями и сопротивлениями, складывающимися в предпринимательстве в настоящее время. В итоге обосновывается, что на фоне происходящих событий российское предпринимательство может выступить не просто драйвером посткризисного восстановления, но и стать локомотивом реиндустриализации экономики, а его роль в усилении тенденции экономического роста может быть активизирована через успешную модификацию предпринимательских экосистем и ухода от непозитивных институциональных практик.

Ключевые слова: предпринимательская экосистема, трансформация предпринимательского ландшафта, модель преемистости предпринимательского потенциала.
$\mathrm{C}$ овременное российское предпринимательство сосредоточенное в секторе малого и среднего бизнеса, большей частью ориентировано на конечного потребителя, во взаимодействии с которым и формируются предпринимательские экосистемы. Это касается как производства, так и торговли, и сферы услуг. Более четверти экономически активного населения страны занято на предприятиях малого и среднего бизнеса, поэтому их проблемы могут коснуться очень многих, что делает необходимым включение малого и среднего бизнеса в стратегические программы экономического развития. Однако, потрясения 2020 года серьезно изменили социально-экономический ландшафт общества и предпринимательства.

Целью данной статьи является анализ факторов, воздействующих на предпринимательские экосистемы, и разработка модели, описывающей емкость предпринимательского потенциала для экономики в условиях ограничений.

Под трансформацией предпринимательских экосистем авторы понимают существенные финансово-эко- номические, управленческие, технико-технологические, социальные и иные изменения состояния предпринимательства под влиянием глобальных макрофакторов, создающих определенные напряжения и сопротивления в системе как таковой.

Уже в самом начале развернувшегося весной 2020 года экономического кризиса стало очевидно сокращение расходов на конечное потребление, как по причине введенных противоэпидемиологических ограничений, так и в силу моментально возросшей неопределенности относительно будущих доходов, заставивших людей экономить. Как известно, российское общество в среднем не богато, что обусловливает довольно высокую эластичность спроса по доходу на многих рынках. На рисунке 1 видно, что на фоне очень серьезного падения потребительских расходов в апреле и мае текущего года спрос в отдельных сегментах буквально рухнул. В результате этого под удар попали очень многие небольшие компании.

Непрекращающееся давление негативных факторов свидетельствует о том, что предпринимательские экоси- 


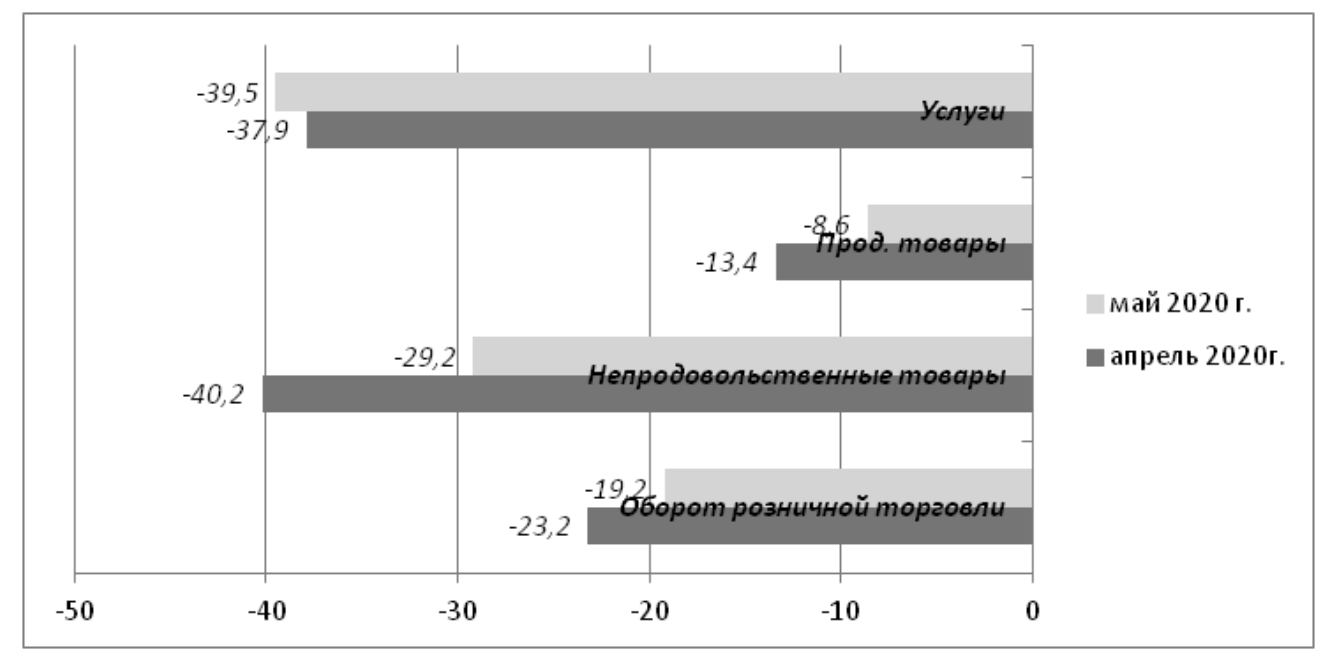

Рис. 1. Падение потребительских расходов в целом и расходов на отдельные категории благ в апреле и мае 2020 г. по сравнению с апрелем и маем 2019 г.

Составлено авторами по данным Росстата

стемы многих малых предприятий, если не разрушаются, то, по крайней мере, вынужденно претерпевают кардинальную трансформацию.

В этой кризисной трансформации экосистем существенную роль может сыграть государство. Российское предпринимательство, переживавшее кризисы 1998, 2008-2009, 2014-2015 годов, столкнулось с беспрецедентной угрозой закрытия в 2020 году. Как видно из аналитики, проблема возникла не из-за условий, институтов или организационной неоптимальности. Первопричина - падение спроса, из-за которого возник шок в столь долго выстраиваемых предпринимательских экосистемах. А в них все элементы взаимосвязаны, поэтому, возникший в экосистеме шок не исчезает, рефлексивно отражаясь на положении всех ее элементов, в случае крушения порождает “эффект домино”, а поэтому требует для своего гашения перенастройки всей системы. Опасность представляет то, что цепочки поставок, налаженные между компаниями, могут непредсказуемо обрываться из-за резкого сокращения расходов в различных рыночных сегментах, а также, как показала практика, из-за несимметричного вынужденного закрытия на время эпидемий. Только скорейшее максимальное восстановление спроса решит возникшие у компаний проблемы и восстановит их экосистемы, на что уйдет время. А до этого момента необходима прямая государственная поддержка, которая станет стабилизатором ситуации.

В России на данный момент не создано гибкой системы социальной поддержки граждан и поддержки малого бизнеса в условиях глубокого кризиса. Они только начали формироваться и, несомненно, станут важным элементом трансформирующихся предпринимательских экосистем, но их адаптация к новым условиям займет довольно много времени. Пока же мы видим, что бизнес пострадал очень сильно и глубина ухудшения ситуации полностью еще не исчерпана. Неопределенность, связанная с тем что, когда вернутся люди к работе и в каком объеме становится едва ли не самым тяжелым ударом, который коронавирусный кризис наносит по российскому бизнесу.

Объявленный пакет государственной помощи бизнесу, безусловно, позитивен и будет определять фарватер, в котором будут развиваться обновленные предпринимательские экосистемы. Но дело в масштабах. Если в западных странах государство взяло на себя практически все фиксированные расходы компаний, закрытых по решению властей, то в России подобные действия носят частичный характер и предприняты не во всех регионах. Рекомендации со стороны властей бизнесу льготировать друг друга работают слабо, так как задействуются длинные цепочки, возможный кризисный обрыв которых может поставить под угрозу хрупкие предпринимательские экосистемы. Бизнесу явно нужен “плательщик в последней инстанции", которым частная компания не может выступать. А, значит, эту роль и возьмет на себя государство.

Насколько быстро предпринимательство оправится от кризиса, будет во многом определяться темпом восстановления спроса после карантина. Следует понимать, что потребительское поведение сейчас поменяется из-за смены предпочтений. Даже если предположить скорейшее открытие малых предприятий в сфере услуг (магазины, отели, кафе, рестораны, фитнесс-центры), то ходить в них буду в разы меньше людей. Многие адаптировались к изоляционному поведению и сократили расходы на услуги. Кроме того, за период изоляции люди серьезно исчерпали свои сбережения, а текущие заработки у многих снизились. Очевидно, что после вы- 
хода из карантина стремление экономить на всем будет проявляться довольно долго. В такой ситуации немалый сегмент малого и среднего предпринимательства, ориентированного на конечного потребителя, так и не сможет адаптироваться к шоку, утратив платежеспособный сегмент своей предпринимательской экосистемы. Такие экономические сдвиги неизбежно приведут к изменению предпринимательского ландшафта в стране. При этом изменится не только отраслевая структура бизнеса, адаптируемая под смену предпочтений потребителей, но и структура собственности и размер компаний. Объективные кризисные трудности повлекут за собой волну слияний и поглощений, вследствие которой оставшиеся на рынке компании станут, в среднем, крупнее, освобождая ниши для появления совершенно новых предпринимательских бизнесов.

Рассмотрим подробнее меры антикризисной поддержки, предлагаемые Правительством РФ в части, касающейся малых и средних предприятий, чтобы проследить формирующиеся контуры новых предпринимательских экосистем.

Постановлением Правительства приняты налоговые меры по поддержке бизнеса и предпринимателей, занятых в пострадавших от коронавируса отраслях, которые предусматривают отсрочку по большинству налоговых платежей и запрет на внеплановые проверки. В апреле и мае 2020 года предпринимателям и предприятиям малого бизнеса предоставлялись субсидии на выплату заработной платы работникам, что частично компенсировало их затраты на сохранение занятости. Такой шаг позволяет сберечь предпринимательские ресурсы для восстановления и дальнейшего роста. Часть малых предприятий, соответствующих утвержденным правилам, получают для тех же нужд беспроцентные кредиты. Кроме того, были расширены программы льготного кредитования малого и среднего бизнеса и возможности реструктуризации ранее осуществленных займов, введены кредитные каникулы и отсрочки по аренде государственного и муниципального имущества для предприятий, наиболее пострадавших от эпидемии, в том числе, малым, и снижены требования к обеспечению государственных контрактов. Наиболее значимым антикризисным шагом государства стало снижение тарифов по страховым взносам для предпринимателей, выплачивающих заработную плату, с 30 до 15\% от фонда оплаты труда. Таким образом, стимулируется сохранение высокого уровня заработной платы, что оказывает дополнительное стимулирующее воздействие на экономику. Именно эта мера признается самими представителями бизнеса, как наиболее действенная в сложившихся условиях при отсутствии широкого безвозмездного субсидирования расходов. Такие изменения позволили существенно снизить нагрузку на фонд оплаты труда и высвободить часть средств для сохранения заработных плат либо для пополнения оборотного капитала. Мера носит долгосрочный характер и будет применяться и в последующих периодах: окончательный срок ее действия не обозначен. Таким образом, малому бизнесу задается довольно большой горизонт планирования деятельности, что исключительно важно в условиях экономической нестабильности и неопределенности.

Следует понимать, что принятые меры, как и никакие другие из возможных, не гарантируют спокойного прохождения малого бизнеса через затяжной кризис. Ведь налоговые отсрочки и безвозмездные или частично субсидируемые кредиты в любом случае предполагают возобновление платежей через какое-то время. А для этого бизнесу необходимо, чтобы к нему вернулись покупатели, гарантии чего сегодня нет. Более того, окончательно неизвестны и сроки полного снятия эпидемиологических ограничений, что позволило бы предприятиям рассчитать требуемый запас финансовой прочности для выживания. Еще раз отметим, что в такой ситуации необходимо появление "плательщика в последней инстанции", берущего на себя возникающие убытки, которые бизнес, связанный обязательствами перед банками, арендодателями и поставщиками, просто не может взять на себя. Именно эту роль и взяло на себя государство во многих странах, пойдя на беспрецедентные бюджетные дефициты и оказав безусловную безвозмездную поддержку домашним хозяйствам и предприятиям.

В России государство выбрало стратегию оказания адресной помощи, что в случае с домашними хозяйствами, что в случае с бизнесом. Несмотря на то, что доступ к большинству инициатив антикризисной программы предполагает соблюдение ряда условий (попадание в реестр наиболее пострадавших от эпидемии отраслей, предварительное сохранение штатной численности персонала и т.д.), уже с середины апреля предприятия малого бизнеса и домохозяйства стали получать помощь. К настоящему времени тысячи предприятий возобновляют работу по мере снятия ограничительных мер.

Таким образом, экономические власти осуществляют комплексный подход к антикризисной поддержке экономики, применяя широкий спектр мер денежно-кредитной (через снижение процентных ставок и вливание дополнительной ликвидности) и налогово-бюджетной политики (через дотирование отдельных категорий физических лиц, а также льготирование и субсидирование отдельных категорий предприятий, в том числе малых). Именно поэтому мы и можем говорить о формировании нового предпринимательского ландшафта и обновлении экосистем. Высвобождая ресурсы предпринимателей для успешного преодоления кризиса, Правительство действует с двух сторон. Во-первых, предоставляет возможность получить дополнительные средства при соблюдении определенных условий. Во-вторых, осво- 
бождает от некоторых обязательных платежей и предоставляет право на отсрочку от других платежей. Все это позволяет бизнесу обеспечить временную концентрацию недостающих средств и переформировать свои ресурсы для работы в новых условиях и адаптироваться к обновленному режиму работы, который детерминируется динамикой эпидемиологической ситуации. Создаваемые при активном участии властей обновленные форматы взаимодействия с бизнесом уже начали воздействовать на обновление предпринимательских экосистем, которые позволят компаниям адаптироваться к изменившейся ситуации и перегруппировать свои ресурсы. При этом не случайно в условиях глобальной неопределенности, когда у предпринимателей пока не выработалось новых идей, инициатором изменений становится государство.

Еще одним контуром новых предпринимательских экосистем является то, что власти однозначно не готовы секвестировать бюджетные расходы. Значит, те, кто ориентирован на участие в госконтрактах, остаются более защищенными. Стратегии у самих предпринимателей на данный момент нет, и это заметно во всем мире, не только в России. Большинство занимают выжидательную позицию. Многое держится на уверенности в лучшем исходе. Инерция надежды на быстрое и относительно безболезненное восстановление стабильности очень велика.

Как и любой большой кризис, события 2020 года сгенерируют новые точки роста. И первыми, кто начнет осваивать их потенциал, будут не госкомпании, а именно предприниматели. Задача государства на этом этапе поддержать. Ведь, речь идет о реальной возможности провести реиндустриализацию российской экономики. Благоприятные условия для этого формирует сегодня конъюнктура мирового энергетического рынка и механизм увязки с ней российского валютного рынка.

Дело в том, что российский рубль в последние два десятилетия приобрел очень тесную зависимость от объемов экспорта, которые, в свою очередь, в значительной степени определяются сырьевой выручкой. Наметившееся устойчивое долгосрочное снижение цен на нефть уже во втором квартале 2020 года привело к значительному сокращению экспортных доходов, что задаст понижательный тренд курсу рубля. В такой ситуации импортные товары на внутреннем рынке всегда начинают расти в цене. Учитывая значительную долю импорта в потреблении, динамика которой за последние двадцать лет показана на рисунке 2, привычная потребительская корзина начнет дорожать. При стагнирующих, а то и вовсе сокращающихся доходах такая ситуация формирует запрос на импортозамещение.

Вместо ставших недоступно дорогими импортных товаров спрос начнет переключаться на их отечественные аналоги. Очень схожий процесс наша экономика переживала с конца 1998 и до 2002 года. Несмотря на некоторые потери в качественных характеристиках потребления, этот процесс следует считать позитивным для общества. Мобильные предприниматели, как показал наш опыт двадцатилетней давности, способны достаточно быстро наладить производство потребительских товаров взамен импортных и, тем самым, создать новые предпринимательские экосистемы с новыми же цепочками поставок и распределения произведенных товаров.

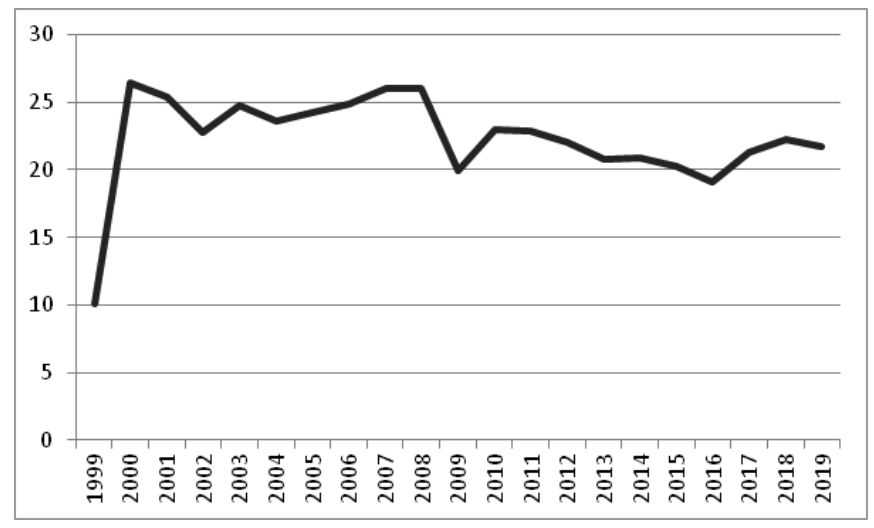

Рис. 2. Изменение доли импорта в потреблении в России в 1999-2019 гг.

Неизбежно начнет расти занятость в производственном секторе, а также и в торговле, и предприниматели дадут экономике шанс выйти из кризиса, да еще и с обновленной в пользу новой индустриализации структурой. Сегодня для этого принципиально важно участие государства в создании обновленных предпринимательских экосистем, что и было отмечено выше. На рисунке 3 показана взаимосвязь между динамикой обменного курса рубля и экономической активностью малых предприятий в России, которая сформировалась за минувшие два десятилетия. Из графика можно сделать вывод, что предпринимательская активность позитивно реагирует на стабильность обменного курса, а также нарастает по мере обесценения национальной валюты. Для нас больший интерес представляет левая часть графика. Рост же деловой активности при укрепляющемся рубле, так же отраженный на графике, относится к периоду 2004-2008 годов, когда высокие темпы роста экономики перекрывали влияние фактора укрепляющегося рубля.

Следует понимать, что на фоне падающих доходов населения спрос в секторе услуг сократится по сравнению с докризисным, поскольку потребительские приоритеты и предпочтения, как было обозначено выше, меняются из-за кризиса.

И там часть бизнесов будет закрыто. Опять же, рабочие места появятся в производственной сфере. А рост 


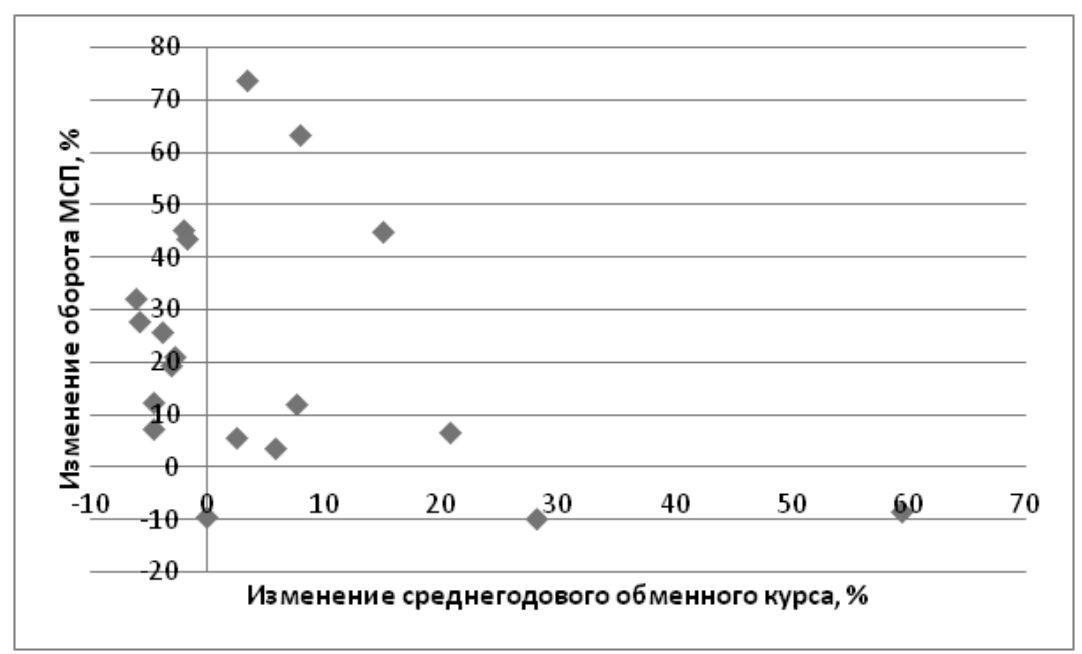

Рис. 3. Взаимосвязь между изменением среднегодового курса рубля к доллару и изменением оборота предприятий малого и среднего бизнеса в 2000-2018 гг.

доходов производственников позволит многим вернуться к потреблению услуг через несколько лет. Поэтому ключевой вектор государственной поддержки предпринимательства должен быть направлен на оказание помощи производственным предприятиям, чьи экосистемы должны быть адаптированы к новым условиям в первую очередь.

Вышеприведенный анализ состояния макрофакторов предпринимательских экосистем российского бизнеса на фоне рассмотрения эволюции предпринимательства и обзора мировых практик успешного управления им позволяет сформулировать в первом приближении модель, описывающую емкость предпринимательского потенциала для экономики нашей страны. Еще раз отметим, что на фоне глубокого кризиса, вызванного, в том числе, серьезными внешними шоками, мобильный предпринимательский сектор становится приоритетным инструментом ускорения выхода всей экономики из сложившейся ситуации. Сегодня для экономики принципиально важна именно скорость реакции при адаптации к непозитивным изменениям, что не позволит уровню благосостояния населения провалиться слишком глубоко. На повышение этой скорости и должна сработать предпринимательская экосистема. Вышеизложенное позволило авторам сформулировать гипотетическую модель емкости предпринимательского потенциала (формула).

$$
\mathrm{E}_{\text {пп }}=Э \Phi \times \frac{\Pi Л \times \mathrm{K}_{\text {пэ }}}{\text { РИ }}
$$

где: $\mathrm{E}_{n п}$ - емкость предпринимательского потенциала;

ЭФ - Экономические факторы;

ПЛ - предпринимательский ландшафт;

$\mathrm{K}_{\text {пэ }}$ - качество предпринимательской экосистемы;

\section{РИ - ригидность институтов.}

Числитель этой формулы характеризует напряжение, испытываемые предпринимательскими экосистемами, под влиянием макрофакторов позитивного характера. Знаменатель характеризует сопротивления в экосистемах вследствие макрофакторов, противодействующих развитию предпринимательства.

То есть, предпринимательский ландшафт, усиленный достигнутым в процессе формирования и модификации качеством предпринимательской экосистемы, делает экономику более адаптивной к изменениям. В то же время, ригидность институтов, определяемая укоренением непозитивных институциональных практик, оказывает тормозящий эффект на скорость адаптации экономики. При этом текущие благоприятные экономические факторы играют роль мультипликатора, преумножающего усилия по модернизации институциональных факторов. Наши продолжающиеся исследования позволят получить количественные эмпирические оценки значимости каждого из компонентов данной модели, в том числе и мультипликативной мощности экономических факторов.

Подводя итог вышеизложенному, можно сделать следующие выводы:

1. Кризис 2020г. открыл перед российской экономикой реальную возможность перейти к реиндустриализации, используя инерцию самого кризиса. Это болезненный и трудный путь, но он становится едва ли не единственным вариантом структурного обновления нашей экономики.

2. Малый и средний бизнес способны поддержать развернутую дешевеющей национальной валютой волну импортозамещения. Предпринимательство, поддерживаемое государством, может сы- 
грать и обязательно сыграет самую главную роль в реализации и ускорении этого процесса.

3. Часть существовавших ранее предпринимательских экосистем не смогут продолжить эффективную работу при новых реалиях предпринимательского ландшафта. Реализуемые же государством меры поддержки, модифицирующие предпринимательские экосистемы, становятся первыми элементами в создании новых предпринимательских экосистем, закладывающих предпринимательский вектор траектории развития новой российской экономики.

\section{ЛИТЕРАТУРА}

1. 0 развитии малого и среднего предпринимательства в Российской Федерации [Электронный ресурс]: федер. закон от 24.07.2007 N 209-Ф3 (с последующими редакциями). Доступ из справ.-правовой системы «КонсультантПлюс».

2. 0 Концепции государственной политики поддержки и развития малого предпринимательства в Свердловской области на 2002-2020 годы [Электронный ресурс]: Постановление Правительства Свердловской области от 3 октября 2002 г. N 1262-ПП (с последующими редакциями). Доступ из справ.-правовой системы «КонсультантПлюс».

3. Основные направления деятельности Правительства Российской Федерации на период до 2024 года (утв. Правительством РФ 29.09.2018) [сайт]. КонсультантПлюс. url http://www.consultant.ru/document/cons_doc_LAW_307872/ (дата обращения: 13.11.2020).

4. Основные направления бюджетной, налоговой и таможенно-тарифной политики на 2019 год и на плановый период 2020 и 2021 годов (утв. Минфином России) [сайт]. КонсультантПлюс. url http://www.consultant.ru/cons/cgi/online.cgi?req=doc\&amp;ts=203105621718476845250367892238785\&amp;cacheid $=2973$ FCOA2FE796138451725D9A1531BB\&amp;mode=splus\&amp;base $=$ LAW\&amp;n=308390\&amp;rnd=0.842668489494022\#004741848842898688 (дата обращения: 13.11.2020).

5. Глобальный мониторинг предпринимательства. Россия 2019. Отчет Global Entrepreneurship Monitor (GEM) // Официальный сайт Высшей школы менеджмента Санкт-Петербургского государственного университета. [Сайт]. URL: http://www.gsom.pu.ru/research/eship/projects/gem/.(дата обращения: 30.06.2020).

6. Д. Медведев: Доля малого бизнеса в ВВП РФ составила 13-15\% : [сайт]. РосБизнесКонсалтинг. url: http://top.rbc.ru/economics/18/02/2008/142463.shtml (дата обращения: 10.12.2019).

7. Демография организаций [сайт]. Федеральная служба государственной статистики (Росстат). url: http://www.gks.ru/bgd/regl/b11_01/lssWWW.exe/Stg/ d05/pred-2.htm (дата обращения: 26.08.2020).

8. Демография организаций в июне 2019 года [сайт]. Росстат. url: http://www.gks.ru/wps/wcm/connect/rosstat_main/rosstat/ru/statistics/enterprise/reform/\# (дата обращения: 21.09.2020).

9. Доля малого и среднего бизнеса в ВВП [сайт]. Вести. Экономика. url: https://www.vestifinance.ru/infographics/5337 (дата 06ращения: 20.09.2020).

10. Каждый третий россиянин готов к открытию собственного бизнеса. ВЦИОМ. [Сайт]. URL: http://wciom.ru/index.php?id=80 (дата 06ращения: 27.05.2020).

11. Малое и среднее предпринимательство в России, 2019г.: [сайт]. url: http://www.gks.ru/bgd/regl/b17_47/Main.htm (дата 0бращения: 28.08.2020).

12. Основные показатели деятельности малых предприятий: [сайт]. Федеральная служба государственной статистики (Рoccтат). url: http://www.gks.ru/bgd/ regl/b14_14p/lssWWW.exe/Stg/d02/12-08.htm (дата обращения: 26.09.2020). 